\title{
The Success of Cisco Systems, Inc.'s Human Resource Management Strategy
}

\author{
Han Chen \\ School of Government, Beijing Normal University, Beijing, China \\ Email: bnugychenhan@126.com
}

How to cite this paper: Chen, H. (2017) The Success of Cisco Systems, Inc.'s Human Resource Management Strategy. Journal of Service Science and Management, 10, 206- 215. https://doi.org/10.4236/jssm.2017.103018

Received: April 8, 2017

Accepted: May 20, 2017

Published: May 23, 2017

Copyright $\odot 2017$ by author and Scientific Research Publishing Inc. This work is licensed under the Creative Commons Attribution International License (CC BY 4.0).

http://creativecommons.org/licenses/by/4.0/

\begin{abstract}
This study investigates the human resource management strategy in a successful Internet company, Cisco Systems, Inc. Through the analysis of the company's human resource management system, the study has found that Cisco has chosen soft HR model, built seven-step recruitment process, raised 11 performance factors and formed special employment philosophy. Based on the findings, the study has summarized some suggestions of human resource management for Internet companies.
\end{abstract}

\section{Keywords}

Cisco Systems, HR Model, Recruitment and Selection Process, Performance Management, Employment Philosophy

\section{Introduction}

Founded in 1984 in California, Cisco Systems, Inc. which begins with producing routers now has become the leading giant in computer and networking industry throughout the world. After more than 20 years of development, Cisco has become the world's leading provider of network solutions. Since listing in 1990, Cisco's annual revenue has risen from $\$ 69$ million to $\$ 49.161$ billion in 2016, getting net income of $\$ 7.9$ and ranking 183rd in the world's top 500 enterprises in 2016 [1]. According to Cisco's annual report (2013) [2], it is said that 89 percent of employees are proud to work at Cisco and it was ranked number 42 on the Fortune "100 Best Companies To Work For" list. Human resource management affects employees' work efficiency and their evaluation of organization. Cisco has achieved rapid pace of development, outstanding organizational performance and high employee satisfaction, which illustrates the necessity to analyse the success of its human resource management strategy. 


\section{Literature Review}

\subsection{Modules of Human Resource Management}

Human resources are the most critical resources in all social resources, which are also important for enterprises. Human resource management means the scientific and rational allocation of human resources in an organization or enterprise in order to improve work efficiency and optimize human resources. The six modules of human resource management are a summary of the content covered by enterprise human resource management through the way of module division, which specifically refers to: human resources planning, recruitment and allocation, training and development, performance management, compensation and benefits management, employee relationship management [3]. The subsequent analysis will follow this framework of the six modules.

\subsection{Evaluation of HRM Methods}

One of the most critical aspects of HRM is evaluating HRM methods and measuring their results. Even the most carefully planned and executed HRM programs are meaningless without some way to judge their effectiveness and confirm their credibility. The evaluation of HRM methods and programs should include both internal and external assessments [4]. Internal evaluations focus on the costs versus the benefits of HRM methods, whereas external evaluations focus on the overall benefits of HRM methods in achieving company goals. Larger human resource departments often use detailed, advanced data gathering and statistical analysis techniques to test the success of their initiatives. The results can then be used to adjust HRM programs or even to make organizational changes. The subsequent analysis will discuss how the HRM of Cisco meets the internal and external need of organizational development.

\section{Case Analysis}

\subsection{Human Resources Planning}

There are two approaches to human resource management. One is hard approach, while another is soft approach. Scholars have distinguished between hard and soft approaches of human resource management, typically by the Michigan model and Harvard model respectively. Hard HRM focuses on the costs incurred by the human resources of a firm in order to manage numbers effective, keeping the workforce closely matched with requirements in terms of both bodies and behavior. Soft HRM is an approach stressing the human aspects of HRM. It concerns the communications and motivations. Employees are involved in the determining realizing strategic objectives [5].

As for Cisco, it takes the soft approach to human resource management, to be more specifically, influenced more by the Harvard model. The analytical framework of the Harvard model consists of six basic components [6]. This model stresses the human aspect of HRM and is more concerned with the relationship between employer and employees. The model highlights the interest of different 
stakeholders and recognizes the influence of situational factors. Cisco is a company that cares a lot for the corporate social responsibilities. Besides, Cisco is also an innovative company, which values its employees as company's talent assets. Therefore, when Cisco is making the human resource management decisions, it will take the stakeholders value and situational factors into consideration. And the emphasis on people resulted in employees' highly commitment for the company, which in a long-term generates more benefits for all.

\subsection{Recruitment and Selection}

One of the core business processes of Human Resources is to identify and recruit people with the appropriate skills, abilities, knowledge and experience to fill jobs in the work organization [7]. No matter when the economy is booming or facing depression, employers always have the need to find qualified employees. When a company designing recruiting activities, the sources to target and the methods to use are among the most important issues to address. And experienced companies choose recruiting sources and methods based on the companies' specific hiring needs and objectives [8]. Therefore, how to access the potential employees as well as use the resource to sort through all of the candidates to find qualified ones has always been HR managers' great concern.

Developing an inclusive workplace starts with recruitment from a diverse pool of candidates. Different sources of candidates can be reached using different methods of recruiting. Basically, there are two sources of potential applicants: one is called the external labor market, while another is named the internal labor market. When it comes to the recruiting process, big organizations always use both sources to find qualified person.

As one of the leading companies in the rapidly growing Internet industry, Cisco requires a large number of highly skilled professionals and talented employees to filling the new position needs. In order to sustain company's continued growth, the recruiting efforts should be focused on finding the right person for the right position efficiently. There are three main practices in Cisco.

Firstly, Cisco pays attention to recruiting people who are in line with Cisco values. Cisco takes a rigorous interview with job applicants. In particular, the interviewers include the human resources manager as well as prospective bosses and colleagues. The methods ensures implement employment strategies based on the values of the search, which can reduce staff training costs and drain costs, and improve staff efficiency.

Cisco believes that the diversification of staff can enable them to have the opportunity to contact with new ideas, get better decision-making and bring them a competitive advantage. Cisco has established a wide range of recruitment networks to recruit people with diverse backgrounds, cultures, skills and perspectives. According to statistics in 2014, ethnic minorities accounted for about $46 \%$ of the total number of Cisco employees in the United States, women accounted for about $26 \%$ of the number of employees in the United States, and in the world, female employees accounted for $23 \%$. 
The last but not the least, after candidates' application, it comes the most important part of recruitment-selection. Organizations have to find a way to measure and assess applicants in order to find the right one. Rather than trust to luck, companies are using more sophisticated selection methods to making good selection decisions. Here is a list of the most common selection methods:

- $\mathrm{CV}$ and/or application form;

- Interview (F2F, phone);

- Assessment centers;

- References;

- Psychometric testing;

- Work sampling;

- Biodata.

In Cisco, the selection process varies by positions and the chosen selection methods will depend on many factors. As argued by Wilk and Cappelli [9], it is not simply a case of "more is better". Selection methods will depend on the characteristics of the work and the level of pay and training. For example, some positions in Cisco need professional backgrounds including science, technology, engineering, and mathematics. So these applicants must receive certain ability assessment and the results are mainly depend on the assessment. Moreover, Cisco even launched several online testing for applicants to assess themselves. Cisco developed several career certifications for those specific positions. For example, the CCNA (Cisco Certified Network Associate) is an IT certification to validate candidates' ability to install, monitor, and troubleshoot network infrastructure products. However, other positions that related to the managerial or logistic team do not need such assessment. Selection methods for these positions focus more on the CVs or interviews. The recruitment team will go through applicants' resume and profile carefully and interview them if needed. Final decisions will be a collaborative effort made by collecting all feedback from the profiles or interviews.

\subsection{Training and Development}

CISCO attaches great importance to the learning and development of executives and employees, and hopes that employee training will promote its global business development and the formation of differentiated competitive advantages. CISCO has created a new learning and training solution team. The main objective of the group is to meet the learning needs of the company's core business, and to establish a reasonable allocation and utilization of learning resources within the company wide. At present, the learning and training solutions group is embarking on a change in learning style, while providing different and targeted learning methods for employees. CISCO provides traditional management and leadership curriculum training for its executives, including e-learning, role play, business case studies, and a 360 degree assessment.

\subsection{Performance and Benefits Management}

Apart from recruitment and selection, there are other key processes that call for 
HR managers to spend effort on the performance management and reward management. According to John Bratton (2007), the performance management refers to the series of interrelated practices which are designed to guarantee that employees' whole capabilities and potential are appraised, so that relevant goals can be set for work and development and, through assessment, data on work behavior and performance can be collected and reviewed. While, the reward management refers to the monetary, non-monetary and psychological payments that an organization provides for its employees in exchange for the work they perform. Thus, the performance management and reward management are closely linked together.

In recent years, in order to get a better result of companies' performance, more and more attention has been paid to establishing companies' directions and goals. More importantly, how to measure it as well as improve it become the critical parts. Based on the well-known Peter Drucker's dictum that "if you cannot measure it, you cannot manage it", finding ways to appraise employees' performance has become a major preoccupation in many organizations. Because such appraisal helps managers do many tasks from evaluating how well the company has done in the past to learning how to improve in the coming future. Almost all organizations have some means of evaluating performance, and whichever methods of assessment are chosen, they are considered to have a critical role in the efficient and effective management of the organization [10].

In Cisco, their performance management is mainly rooted in "performance control approach", which as Randell has pointed out that the key stages of this approach is that define work, set measurable targets, perform and assess against targets [11]. Each year, employees of Cisco should set certain goals under discussion with their supervisors. With the guidance of these goals, employees' incomes are closely linked with their performances. Cisco has several assessments throughout the year to manage employees' performance. For example, there is an opportunity for managers and employees to discuss their development opportunities half way through the year, which is called Mid-Year Career Discussion. Moreover, employees need to review their performance and discuss their need for improvement with their managers annually. In addition, if you are a member of sales department, you also need to be evaluated by the method of MBO (Management by Objectives), which focuses attention on what must be accomplished (the goals that employees set before) rather than how it is to be accomplished. Therefore, an employee' individual performance is finally formed through the triple assessments.

Besides clarifying expectations and setting goals, HR managers also have to determine rewards to motivate employees. As it mentioned before, $89 \%$ of employees are proud to work at Cisco and Cisco was ranked number 42 on the Fortune "100 Best Companies To Work For" list. And all these successes are more or less resulted from Cisco's Rewarding System.

In general, an organization can provide two types of reward: one is monetary, while the other is non-monetary. As the Armstrong pointed out that "it is con- 
cerned with both financial and non-financial rewards and embraces the philosophies, strategies, policies, plans and processes used by organizations to develop and maintain reward systems" [12]. Based on that, here comes a concept called Total Rewards, which refers to all of the tools available to the employer that may be used to attract, motivate and retain employees. Here, we owe Cisco's success to their management philosophy of "Total Rewards". Followed by is the list of what Cisco offers in the "Total Rewards":

- Competitive performance-based pay;

- Comprehensive health coverage;

- Long-term savings packages;

- Employee stock purchase plan;

- Time-off policies;

- Health and wellness benefits through our Health Connections program;

- Employee support programs;

- Development and career progression opportunities;

- Flexible work practices;

- A positive work environment;

- Recognitions of achievements.

According to the list above we can see that Cisco's "Total Rewards" not only include the essential salaries, but also contains benefits such as rewarding employees with stock incentives, promoting flexible work practices, affordable health coverage, and a series of employee and family assistance programs. For example: The Life Connection's Health Center to provide health care for Cisco employees and their families; Childcare centers which offer child scholarship that fund for the children of deceased employees. All these reward policies help Cisco's employees to become more productive, more loyal and happier workforces.

\subsection{Employee Relationship Management}

\subsubsection{Fair and Equal Culture}

Nowadays, Cisco is the worldwide leader in Internet Industry, and it has operations in more than 165 countries. Under the circumstance that Cisco doing business across the world, an inclusive and diverse culture has gradually formed. This culture also has great influence on Cisco's employment philosophy.

Such employment philosophy has expressed vividly in Cisco's fair treatment to everyone on the team. In order to form a culture of inclusion and diversity, Cisco need to make sure that all employees are treated equally and have equal opportunities to succeed, regardless of race, gender, disability, or other underrepresented minority status. For example, Cisco not only create more opportunities to bring more women into leadership teams, they also track gender diversity at all stages of hiring process, which helps them develop action plans addressing any areas where calls for additional effort. Another example is that, unlike most Japanese companies' homogeneous employee team, Cisco has a far more diverse workforce. In the United States, nearly half of Cisco's workforce is non-white. 
Nevertheless, people from Asian and Pacific Rim still remain underrepresented in the senior management team. In order to solve this problem, Cisco starts to run a program (Pac-Rim Asian Leadership Development Program) to help those people from Asian and Pacific Rim to develop skills that are useful for senior management [13].

Cisco benefits a lot from this inclusive and diverse culture. The rich mix of perspectives and experiences that the employees bring to the company enables Cisco to understand the needs of their customers around the world better and create more innovative products or services to meet these needs.

\subsubsection{Avoiding Cultural Conflicts}

In recent years, as economic globalization process deepen gradually, an increasingly number of companies are "going outside" as a growth strategy in order to become a more competitive global player. And the methods of cross border merger and acquisitions have among the dominant modes for companies to seek the competitive advantage in a more and more complex and global business economy [14]. Here I will give recommendations for Cisco for its future plan on cross border merger, for example, with a Japanese company.

Before we give an in-depth analysis of this growth strategy, let us understand the definition of cross border merger first. A cross border merger can be defined as a transaction in which "the assets and operations of two companies belonging to two different countries are combined to establish a new legal entity" [15]. The primary intention of cross border merger is aiming to quickly entry to the foreign market and gain more competitive advantages through the combination. However, in fact, most of the cross border merger cases resulted in not achieving their anticipated strategy and financial goals. Therefore, how to serve overseas markets wisely as well as make the merger case works effectively are among the key challenges facing by companies.

To tackle these challenges in cross border merger, the very first factor that should be taken into consideration is the impact of cultural differences on the workplace. A variety of studies have shown that many management concepts, techniques, and systems are greatly influenced by national culture. For example, André Laurent argues that the nationality had three times more influence on the shaping of managerial assumptions than components such as age, education, job position, etc [16]. Therefore, cross border mergers are more likely to encounter the challenges raised by cultural differences. According to the research of Geert Hofstede, there are four cultural factors summarizing different cultures and explain how and why people from different nations behave as they do. These four factors are: "power distance, uncertainty avoidance, individualism, and masculinity" [17].

In our case, Cisco is going to merger with a Japanese company. And we can recognize some of the culture differences based on Hofstede' study (Figure 1).

According to the figures ranked by Hofstede: Power distance Japan has a rank of 54 and the US a rank of 40 . This suggests that the attitude towards these inequalities amongst people is similar in both cultures. However, in the rest three 


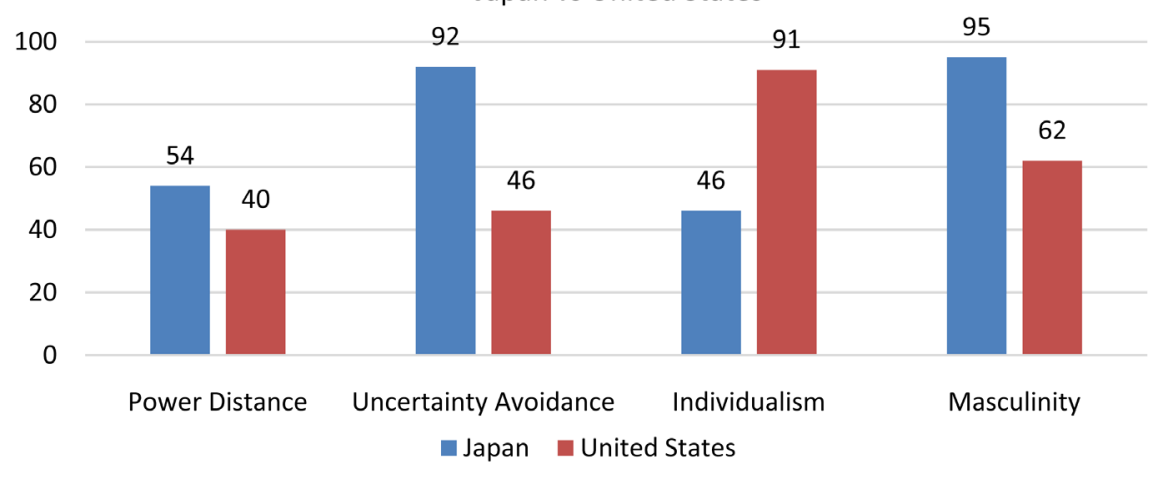

Figure 1. The Hofstede Centre (2014): http://geert-hofstede.com/japan.html [18].

factors, there seem to be a quite gap between the US and Japan, especially in uncertainty avoidance and individualism. At 92 Japan is one of the most uncertainty avoiding countries on earth. Thus it is difficult to take changes in Japan. So if Cisco is going to merger with a Japanese company, it had better not to take great changes to the original company. As for individualism, we also see a significant difference when Japan ranks 46 whereas the US ranks 91. Therefore Americans focus more on their own needs and desires while Japanese have a relatively higher sense of "group". So Cisco should pay attention to the conflict that the US managers might concern on his or her own career needs. At last, the low rank of Japan on masculinity shows that the dominant value in Japan are caring for others and quality of life, while what motivates Americans best lie both in work and leisure pursuits. Still, the US approach might be more assertive and aggressive than Japanese are used to. Therefore, when Cisco has to have a thoroughly clearly understanding of their target country's culture to avoid certain conflicts made by culture clashes.

Besides, the staff policy is also a critical aspect when doing a cross border merger. Basically there are three approaches to the staff policy: ethnocentric approach, polycentric approach, and geocentric approach. However, since Cisco is a computer networking company where innovation plays the essential role, I recommend that the geocentric approach is more suitable for Cisco. As mentioned before, the culture of Cisco is diverse and inclusive, and their recruitment is always emphasize equality. So Cisco should hire more local talents and diversify their leadership team. The approach of geocentric will enable the best use of human resources and inspiring employee's spirit of innovation.

Moreover, there are many other factors Cisco should be aware of in order to make a successful cross border merger. For example, have a better understanding of the legal and economic systems in the target country; editing suitable payment and reward systems; be respect to target country's religion beliefs; last but not least, making practical planning and goals.

\section{Conclusion}

Cisco's strategies on human resource management all aim to create a pleasant and satisfactory working environment, which will best generate employees' tal- 
ent and potential in return. When making policies of HR management, Cisco always takes the current situational factors and their stakeholders' interest into consideration. In this way, it makes it possible for Cisco performs well in this hyper competition market. Though Cisco overall did a satisfactory job for the past several years, there are still something that can be improved. For example, further increase the organizational effectiveness or highlights employee contributions with new reward and recognition programs. To sum up, the secret of Cisco's continued success lies in the Cisco values that its competitors cannot imitate. Customer satisfaction, team spirit, openness, communication, inclusiveness, diversity, innovation and learning, etc., these values are related to each other, together to build the core competitiveness of Cisco.

\section{References}

[1] Cisco Systems, Inc. (2016) 2016 Annual Report. https://materials.proxyvote.com/Approved/17275R/20161014/AR_300358/INDEX. $\underline{\text { HTML }}$

[2] Cisco Systems, Inc. (2013) 2013 Annual Report, http://www.cisco.com/web/about/ac49/ac20/ac19/ar2013/docs/2013_Annual_Repor t.pdf

[3] Kama, M.N. (2002) Human Resource Management System: Personnel Module and System Administration Module. 20-27.

[4] Vveinhardt, J. and Papsiene, P. (2013) Problematics of Application of Human Resource Evaluation Models and Methods to Improve Public Sector Performance. Problems \& Perspectives in Management, 11, 94-105.

[5] Storey, J. (1991) New Perspectives on Human Resource Management. 43-48.

[6] Beer, M., Spector, B., Lawrence, P.R., Quin Mills, D. and Walton, R.E. (1984) Managing Human Assets. Free Press, New York, 17-23.

[7] Bratton, J. (2012) Human Resource Management: Theory and Practice. Macmillan, 41, 3-21. https://doi.org/10.1007/978-1-137-00095-8

[8] Jackson, S.E., Schuler, R.S. and Werner, S. (2000) Managing Human Resources. West Publishing Company, Eagan, Minnesota, 30-35.

[9] Wilk, S.L. and Cappelli, P. (2003) Understanding the Determinants of Employer Use of Selection Methods. Personnel Psychology, 56, 103-124. https://doi.org/10.1111/j.1744-6570.2003.tb00145.x

[10] Kennerley, M. and Neely, A. (2002) A Framework of the Factors Affecting the Evolution of Performance Measurement Systems. International Journal of Operations \& Production Management, 22, 1222-1245. https://doi.org/10.1108/01443570210450293

[11] Beardwell, I. (2000) Personnel Management: A Comprehensive Guide to Theory and Practice. Employee Relations, 22, 523-527. https://doi.org/10.1108/er.2000.22.5.523.2

[12] Armstrong, M., Brown, D. and Reilly, P. (2011) Increasing the Effectiveness of Reward Management: An Evidence-Based Approach. Employee Relations, 33, 106120. https://doi.org/10.1108/01425451111096668

[13] Cisco Systems, Inc. (2013) 2013 Corporate Social Responsibility Report. https://www.cisco.com/assets/csr/pdf/CSR_Report_2013.pdf

[14] Adler, N.J. (1986) International Dimensions of Organizational Behavior. Interna- 
tional Executive, 28, 31-32. https://doi.org/10.1002/tie.5060280112

[15] UNCTAD (United Nations Conference on Trade and Development) (2000) CrossBorder Mergers and Acquisitions and Development. World Investment Report, New York and Geneva.

[16] Laurent, A. (2016) The Cultural Diversity of Western Conceptions of Management. International Studies of Management \& Organization, 13, 75-96. https://doi.org/10.1080/00208825.1983.11656359

[17] Hofstede, G. (2004) Introduction: Geerthofstede's “Culture's Consequences: International Differences in Work-Related Values. The Academy of Management Executive (1993-2005), 18, 73-74. https://doi.org/10.5465/AME.2004.12689661

[18] The Hofstede Centre (2014) The Diagram: Japan vs US. http://geert-hofstede.com/united-states.html

Submit or recommend next manuscript to SCIRP and we will provide best service for you:

Accepting pre-submission inquiries through Email, Facebook, LinkedIn, Twitter, etc. A wide selection of journals (inclusive of 9 subjects, more than 200 journals)

Providing 24-hour high-quality service

User-friendly online submission system

Fair and swift peer-review system

Efficient typesetting and proofreading procedure

Display of the result of downloads and visits, as well as the number of cited articles

Maximum dissemination of your research work

Submit your manuscript at: http://papersubmission.scirp.org/

Or contact jssm@scirp.org 